\title{
Análise não linear de blocos de concreto armado sobre estacas como fundação de aerogerador onshore considerando o atrito lateral entre as estacas e o solo
}

\author{
Non-linear analysis of reinforced concrete pile caps as a foundation of onshore wind turbines \\ considering the lateral friction between piles and the soil
}

Análisis no lineal de bloques de hormigón armado en estacas como cimiento de aerogeneradores

terrestre considerando la fricción lateral entre estacas y suelo

Recebido: 11/11/2021 | Revisado: 16/11/2021 | Aceito: 15/01/2022 | Publicado: 16/01/2022

Diego Lima Dantas
ORCID: https://orcid.org/0000-0001-7693-1838
Universidade Federal do Rio Grande do Norte, Brasil
E-mail: engcivil.diegolima@gmail.com
Daniel Nelson Maciel
ORCID: https://orcid.org/0000-0003-3971-4724
E-mail: dnmaciel@ect.ufrn.br
Universidade Federal do Rio Grande do Norte, Brasi
Joel Araújo do Nascimento Neto
ORCID: https://orcid.org/0000-0003-4842-1587
Universidade Federal do Rio Grande do Norte, Brasil
E-mail: joelneto@ct.ufrn.br
Kaique Yuri Márcio Araújo
ORCID: https://orcid.org/0000-0003-4084-3689
Instituto Federal de Educação, Ciência e Tecnologia do Rio Grande do Norte, Brasil
E-mail: kaiqueyuri@gmail.com
Rodrigo Barros
ORCID: https://orcid.org/0000-0002-7218-2646
Universidade Federal do Rio Grande do Norte, Brasil
E-mail: rodrigo.barros@ufrn.edu.br

\begin{abstract}
Resumo
$\mathrm{Na}$ busca por fontes alternativas para atender à crescente demanda por energia, a produção eólica tem tido destaque devido ao grande potencial para sua utilização no Brasil. Dada a magnitude das fundações de unidades aerogeradoras, a compreensão do seu comportamento estrutural é essencial para a concepção de soluções otimizadas, que reduzam custos e facilitem a implantação desta tecnologia em larga escala. Sob esta óptica, este artigo busca aprofundar os estudos acerca do comportamento estrutural de fundações para aerogeradores onshore, representadas por blocos de concreto armado sobre estacas. Foram desenvolvidos modelos computacionais, via Método dos Elementos Finitos (MEF) com o auxílio do software Ansys Workbench R20, considerando-se a contribuição do atrito lateral do fuste das estacas na condução de cargas ao solo, bem como o recalque das estacas, mediante modelagem numérica não linear. Foram dimensionadas as armaduras de uma fundação de torre eólica e propostas duas organizações distintas de malha: circular (AC) e ortogonal (AO). A partir das simulações realizadas, comparou-se, em diferentes tipos de solo, a distribuição das reações nas estacas e os deslocamentos verticais dos blocos. Observou-se que os modelos armados apresentaram um comportamento próximo ao de blocos rígidos, com uma tendência de uniformização das reações e dos deslocamentos verticais. Ao final, foram determinadas as zonas de fissuração do concreto e verificadas as tensões nas armaduras. Os resultados mostraram que as maiores tensões se deram nos modelos com armadura circular (AC), superiores, em média, 2,06\% aos modelos AO. Tal tendência foi associada ao fato dos modelos AO terem se mostrado mais rígidos que os modelos $\mathrm{AC}$ que, sendo mais deformáveis, impõem às armaduras maiores tensões quando fletidos pelo momento de grande magnitude que atua na fundação.
\end{abstract}

Palavra-chave: Análise estrutural; Fundação de aerogerador; Modelagem Numérica; MEF.

\begin{abstract}
In the search for alternative sources to meet the growing demand for energy, wind production has been highlighted due to the great potential for its use in Brazil. Given the magnitude of the foundations of wind turbines, understanding their structural behavior is essential for designing optimized solutions that reduce costs and facilitate the implementation of this technology on a large scale. From this perspective, this article seeks to deepen the studies on the structural behavior of foundations for onshore wind turbines, represented by reinforced concrete pile caps. Computational models were developed using the Finite Element Method (FEM) with the aid of the Ansys Workbench R20 software, considering the
\end{abstract}


contribution of the lateral friction of the pile shaft in the conduction of loads to the ground, as well as the settlement of the piles, through modeling non-linear numerical. The reinforcements of a wind tower foundation were designed and two different mesh organizations were proposed: circular (CR) and orthogonal (OR). From the simulations carried out, the distribution of reactions in the piles and the vertical displacements of the blocks were compared, in different types of soil. It was observed that the reinforced models presented a behavior close to that of rigid blocks, with a tendency towards uniformity of reactions and vertical displacements. At the end, the concrete cracking zones were determined and the tensions in the reinforcement were verified. The results showed that the highest stresses occurred in the models with circular reinforcement (CR), on average $2.06 \%$ higher than the OR models. This tendency was associated with the fact that the OR models have proved to be more rigid than the CR models which, being more deformable, impose greater stresses on the reinforcement when flexed by the moment of great magnitude that acts on the foundation.

Keywords: Structural analysis; Wind turbine foundation; Numerical modeling; FEM.

\section{Resumen}

En la búsqueda de fuentes alternativas para satisfacer la creciente demanda de energía, la producción eólica se ha destacado por el gran potencial para su uso en Brasil. Dada la magnitud de los cimientos de los aerogeneradores, comprender su comportamiento estructural es fundamental para diseñar soluciones optimizadas que reduzcan costes y faciliten la implantación de esta tecnología a gran escala. Desde esta perspectiva, este artículo busca profundizar los estudios sobre el comportamiento estructural de cimentaciones para aerogeneradores terrestres, representados por bloques de hormigón armado sobre pilotes. Los modelos computacionales se desarrollaron utilizando el Método de Elementos Finitos (FEM) con la ayuda del software Ansys Workbench R20, considerando la contribución del rozamiento lateral del fuste del pilote en la conducción de cargas al suelo, así como el asentamiento de los pilotes, mediante modelado numérico no lineal. Se diseñaron los refuerzos de una cimentación de torre eólica y se propusieron dos organizaciones de malla diferentes: circular (AC) y ortogonal (AO). A partir de las simulaciones realizadas, se comparó la distribución de reacciones en los pilotes y los desplazamientos verticales de los bloques en diferentes tipos de suelo. Se observó que los modelos reforzados presentaron un comportamiento cercano al de los bloques rígidos, con tendencia a la uniformidad de reacciones y desplazamientos verticales. Al final, se determinaron las zonas de fisuración del hormigón y se verificaron los esfuerzos en la armadura. Los resultados mostraron que las mayores tensiones ocurrieron en los modelos con armadura circular (AC), en promedio $2.06 \%$ más alto que los modelos AO. Esta tendencia estuvo asociada a que los modelos AO han demostrado ser más rígidos que los modelos AC que, al ser más deformables, imponen mayores tensiones sobre la armadura cuando se flexiona por el momento de gran magnitud que actúa sobre la cimentación.

Palabras clave: Análisis estructural; Cimentación de aerogenerador; Modelado numérico; MEF.

\section{Introdução}

A necessidade do contínuo aprimoramento das tecnologias de geração de energia por meio de fontes renováveis faz-se cada vez mais necessário em um mundo onde se observa o crescimento excessivo da demanda por energia elétrica. De acordo com o relatório Global Energy Review 2021, da Agência Internacional de Energia (IEA), a demanda mundial por eletricidade está caminhando para seu maior crescimento em mais de 10 anos. Só em 2021, deve haver um aumento de 4,5\%, cerca de 1000 TWh, dos quais $80 \%$ é proveniente de economias emergentes (IEA, 2021).

De acordo com Agra Neto et al. (2020), apesar do grande potencial para a geração eólica no Brasil, os elevados custos associados à instalação dos aerogeradores ainda são um fator limitante para a implantação dessa tecnologia de produção de energia em larga escala, impondo às indústrias eólicas um momento de concorrência acirrada, estando a aquisição de projetos sujeita a diferenças de oferta pequenas do um ponto de vista comercial.

O projeto de implantação de uma unidade aerogeradora está condicionado à capacidade de geração, intensidade e direção dos ventos de uma dada região, e não à sua natureza geotécnica. De acordo com Milititsky (2014), em muitas situações, as turbinas eólicas são locadas em antigas lavouras ou regiões de difícil acesso, com a presença de materiais de baixa resistência, o que dificulta desde a investigação do subsolo até sua instalação.

Devido a produção eólica ainda ser um tema recente no país, não se dispõe de normas brasileiras específicas ou procedimentos técnicos consolidados para o projeto dos componentes das torres eólicas. A experiência de agências reguladoras internacionais e as práticas dos países de origem dos equipamentos, ainda são a principal referência para o desenvolvimento desse tipo de projeto (Nakamura, 2020). 
As soluções estruturais adotadas para a implantação de um parque eólico estão intimamente relacionadas com a localização do empreendimento, se em meio terrestre (onshore) ou marítimo (offshore). Quando executadas no continente, as fundações podem ser feitas com a utilização de sapatas, blocos ou radiers estaqueados, geralmente com grandes dimensões. No mar, as soluções abrangem fundações flutuantes, quando implantadas em águas profundas, e sistemas por gravidade, como como as fundações em caixão e as fundações em cálice pré-moldado em concreto (Chastre \& Lúcio, 2014)

Mendizabal (2014) ressalta que a fundação é um dos poucos elementos de um aerogerador que não tem passado por grandes mudanças, devido, entre outros fatores, ao bom desempenho dos blocos em uma ampla variedade de solos, além da simplicidade construtiva. $\mathrm{O}$ autor destaca, ainda, que vários esforços têm sido direcionados com o intuito de reduzir eficazmente o volume de concreto das fundações e a quantidade de armaduras, sendo desenvolvidas diversas variantes, entre as quais se destacam as lajes com contrafortes ou reforçadas, em contraste às fundações convencionais com borda variável.

Dentre as linhas de pesquisa que tem se dedicado ao estudo do comportamento das fundações de aerogeradores, a investigação da influência de fatores como a geometria da fundação, a interação solo-estrutura e a metodologia de análise (linear ou não linear), tem norteado trabalhos que buscam se aprofundar nesta temática. Neste contexto, este artigo tem como objetivo analisar o comportamento estrutural de fundações de aerogeradores onshore, representadas por blocos circulares de concreto armado apoiados sobre estacas, através de uma abordagem numérica, baseada no Método dos Elementos Finitos (MEF), considerando a não linearidade física dos materiais constituintes da fundação e o atrito lateral entre as estacas e o solo.

\section{Metodologia}

Foram modeladas, com auxílio do programa computacional Ansys Workbench R20, as fundações de um aerogerador onshore, constituídas por um bloco de formato troncocônico apoiado sobre 24 estacas com $41 \mathrm{~cm}$ de diâmetro e 10,0 m de profundidade. Os modelos foram concebidos sob condições de contorno que consideraram o atrito lateral entre as estacas e o solo, além da possibilidade de recalque da fundação. Foram admitidas, também, duas diferentes formas de distribuição para as armaduras dos blocos, totalizando 8 modelos numéricos.

\subsection{Modelos analisados}

A geometria das fundações analisadas é apresentada na Figura 1:

Figura 1. Geometria do bloco.

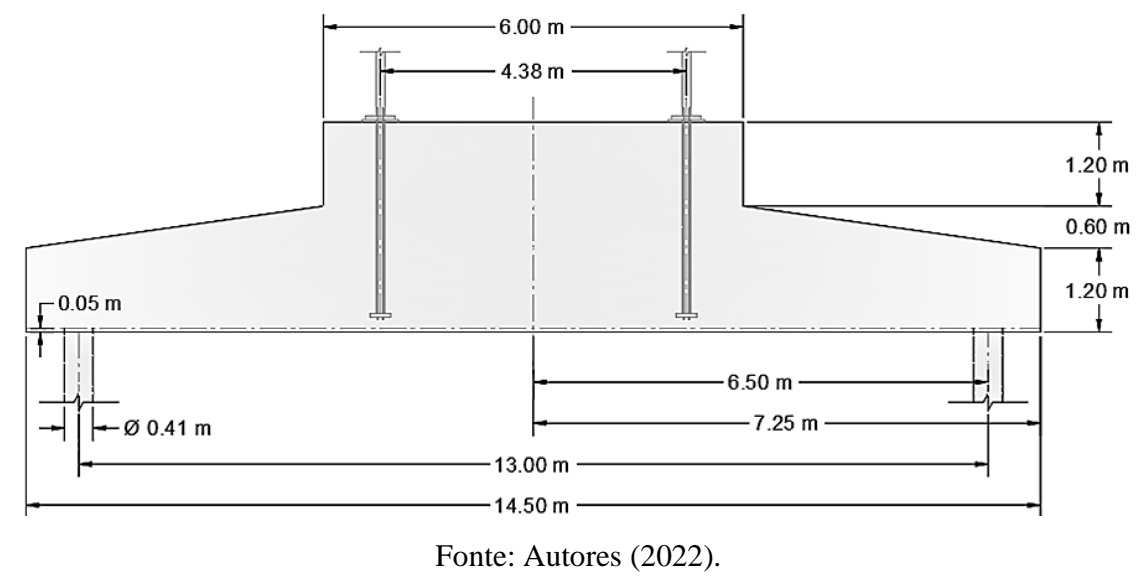

O solo sobre o qual se assentam as fundações foi adicionado aos modelos como um maciço deformável. Foi considerada a existência de uma camada de solo de alta resistência para além da cota da base das estacas, dessa forma, a profundidade do 
maciço se limitou até este nível, onde lhe foi atribuído uma condição de apoio fixo, como indica a Figura 2:

Figura 2. Dimensões do maciço e condições de contorno atribuídas.

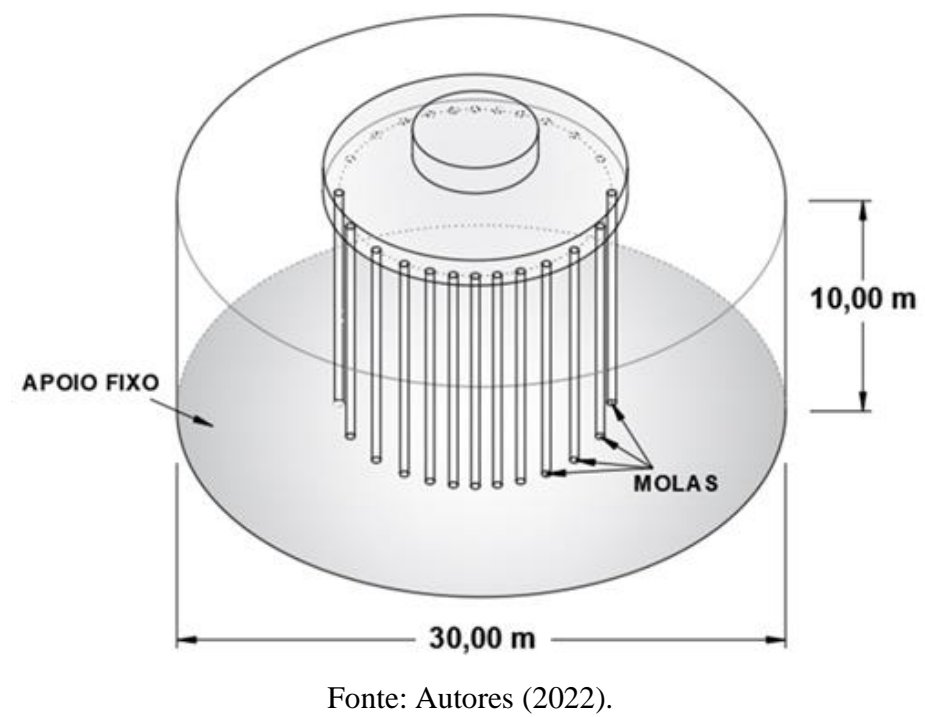

As simulações não incluíram a modelagem do reaterro, sendo aplicadas cargas distribuídas, com valores correspondentes, na região das faces inclinadas dos blocos, para considerar seu efeito. A consideração do recalque das estacas foi conferida com a introdução de apoios elásticos em suas bases, caracterizados por molas cujo módulo de reação vertical foi calculado com base num critério de máxima penetração, a partir da Equação 1:

$$
w=\frac{N}{K_{v}}=\frac{F}{K_{s}^{v} \times A_{f}}
$$

Onde:

w - Recalque direto;

$\mathrm{N}$ - Ação na base da fundação;

$K_{S}^{v}$ - Módulo de reação vertical;

F - Força normal a seção analisada;

$\mathrm{A}_{\mathrm{f}}$ - Área carregada.

Para o recalque w foi adotado o critério de ruptura definido por Décourt (1996), que admite uma deformação da ponta da estaca correspondente ao valor de $10 \%$ de seu diâmetro, para estacas escavadas. Com isso, chegou-se a um coeficiente $K_{S}^{v}$ de $0,198 \mathrm{~N} / \mathrm{mm}^{3}$, adotado para todos os modelos.

A presença do atrito lateral entre as estacas e o solo foi conferida às simulações por meio da utilização de superfícies de contato. Nos modelos analisados, foram utilizadas superfícies de contato do tipo bonded, que restringem o descolamento e o deslizamento entre dois corpos, admitindo uma situação de perfeita aderência (ANSYS, 2013b).

Com relação às armaduras, os blocos foram dimensionados, através de abordagens distintas, de maneira que as barras fossem dispostas em malhas circunferenciais (AC) e ortogonais (AO). A Tabela 1 apresenta um resumo das principais características atribuídas aos modelos: 
Tabela 1. Resumo dos modelos.

\begin{tabular}{lccc}
\hline Modelo & Tipo de solo & Disposição da armadura & Apoio das estacas \\
\hline S0_AC & Sem solo & Circular & Fixo \\
S1_AC & Areia pouco compacta & Circular & Elástico \\
S2_AC & Areia medianamente compacta & Circular & Elástico \\
S3_AC & Areia compacta & Circular & Elástico \\
S0_AO & Sem solo & Ortogonal & Fixo \\
S1_AO & Areia pouco compacta & Ortogonal & Elástico \\
S2_AO & Areia medianamente compacta & Ortogonal & Elástico \\
S3_AO & Areia compacta & Ortogonal & Elástico
\end{tabular}

Fonte: Autores (2022).

\subsection{Caracterização dos materiais}

O bloco e as estacas foram concebidos com concretos das classes $\mathrm{C} 30$ e C20, respectivamente. Para concreto das estacas, foi admitido um comportamento elástico-linear, com o material caracterizado pelo Módulo de Elasticidade Secante $\left(\mathrm{E}_{\mathrm{cs}}=21.000\right.$ MPa). No caso do Coeficiente de Poisson, foi utilizado o valor de $v=0,2$, para todos os concretos.

Ao concreto empregado no bloco foi associado um comportamento não linear, sendo atribuídos parâmetros relacionados ao seu desempenho em situações de tração (concreto fissurado) e compressão (concreto plastificado). Para o concreto fissurado, foram conferidos coeficientes relativos à transferência de esforços de cisalhamento $\left(\beta_{\mathrm{a}}\right.$ e $\left.\beta_{\mathrm{f}}\right)$, apresentados na Tabela 2 . Também foi determinada a resistência última a tração $\left(\mathrm{f}_{\mathrm{ct}, \mathrm{m}}\right)$ com base no item 8.2.5 da ABNT NBR 6118:2014.

Tabela 2. Propriedades do concreto dos blocos na tração.

\begin{tabular}{ccc}
\hline Parâmetro & Descrição & Valor \\
\hline$\beta_{a}$ & Coef. de transferência de cisalhamento através de fissura aberta & 0,2 \\
$\beta_{f}$ & Coef. de transferência de cisalhamento através de fissura fechada & 0,8 \\
$f_{c t}$ & Resistência Última à Tração & $2,90 \mathrm{MPa}$ \\
\hline
\end{tabular}

Fonte: Autores (2022).

No que se refere ao comportamento na compressão, foi adotado um modelo multilinear isotrópico, associado a uma curva tensão-deformação elaborada com base no item 8.2.10.1 da ABNT NBR 6118:2014 e ilustrada pela Figura 3:

Figura 3. Relação constitutiva do concreto C30 à compressão.

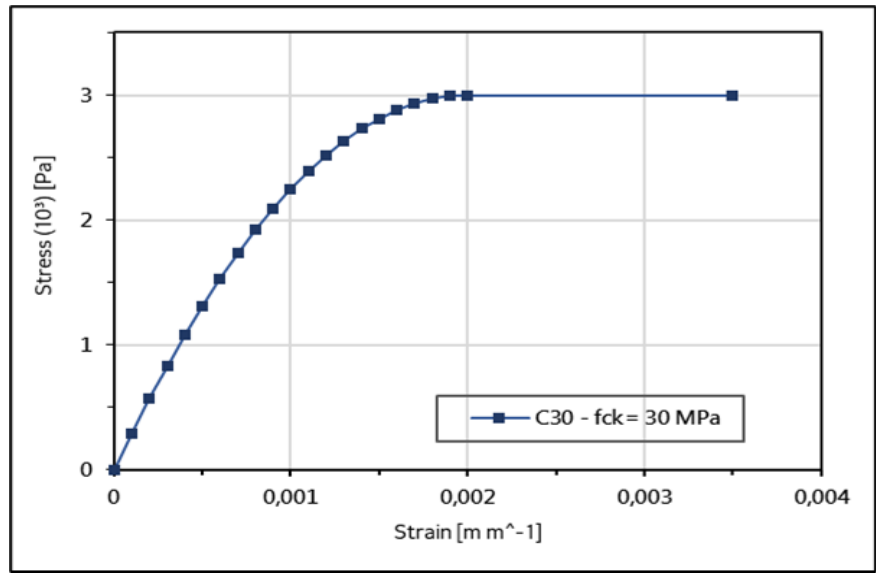

Fonte: Autores (2022). 
O aço foi caracterizado segundo o critério de plastificação de Von-Mises, admitindo um modelo elastoplástico perfeito. No Ansys, tal modelo pode ser empregado através de um sistema isotrópico bilinear, definido por variáveis como o Módulo de Elasticidade, a Tensão de Escoamento e o Módulo de Elasticidade Tangente (ANSYS, 2013c). Nos modelos analisados, foi empregado o aço CA-50 em todas as armaduras, e atribuídos, para as variáveis citadas, os valores de $210 \mathrm{GPa}, 500 \mathrm{MPa}$ e 0 , respectivamente, como ilustra a Figura 4:

Figura 4. Sistema Isotrópico bilinear para o aço.

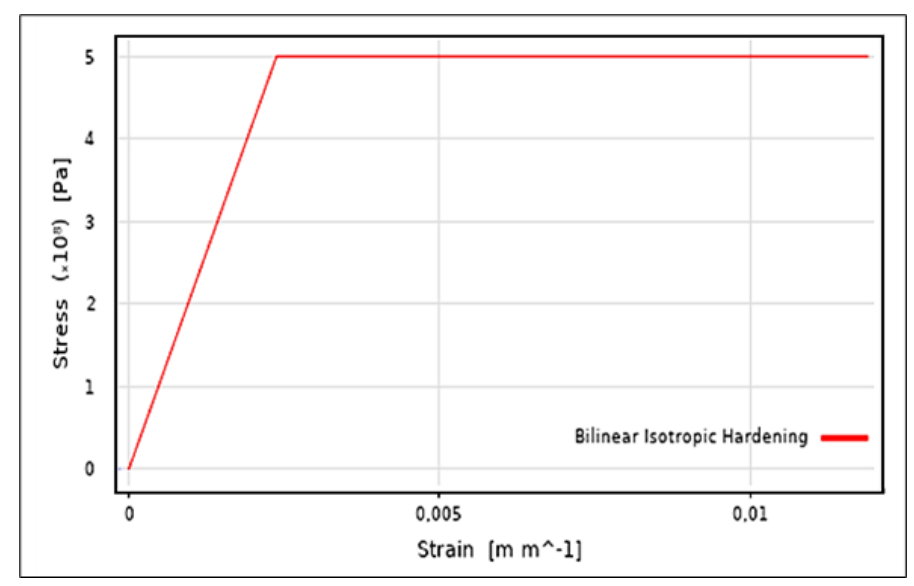

Fonte: Autores (2022).

Os solos foram modelados como maciços tridimensionais de comportamento elástico-linear. A Tabela 3 apresenta um resumo das propriedades atribuídas aos diferentes tipos de solo, estabelecidas com base em dados geotécnicos.

Tabela 3. Parâmetros adotados para o solo dos modelos S1, S2 e S3.

\begin{tabular}{cccc}
\hline Tipo de solo & Peso específico $\left[\mathbf{k N} / \mathbf{m}^{\mathbf{3}}\right]$ & Módulo de elasticidade [MPa] & Coef. de Poisson \\
\hline Areia Pouco Compacta & 16 & 20 & 0,3 \\
Areia Medianamente Compacta & 18,5 & 50 & 0,3 \\
Areia Compacta & 19,5 & 100 & 0,3 \\
\hline
\end{tabular}

Fonte: Araújo (2018).

\subsection{Modelagem numérica}

O concreto foi simulado com a utilização de elementos finitos tridimensionais do tipo CPT215, representados por um prisma de oito nós, com cada nó apresentando três graus de liberdade, referentes às translações nos três eixos, podendo ser adicionados mais dois graus de liberdade extras por nó, associados à regularização de gradiente implícita, sendo ativados por meio de uma opção por comandos APDL (ANSYS, 2013a). A Figura 5 detalha as tipologias do elemento CPT215: 
Figura 5. Elemento CPT215.
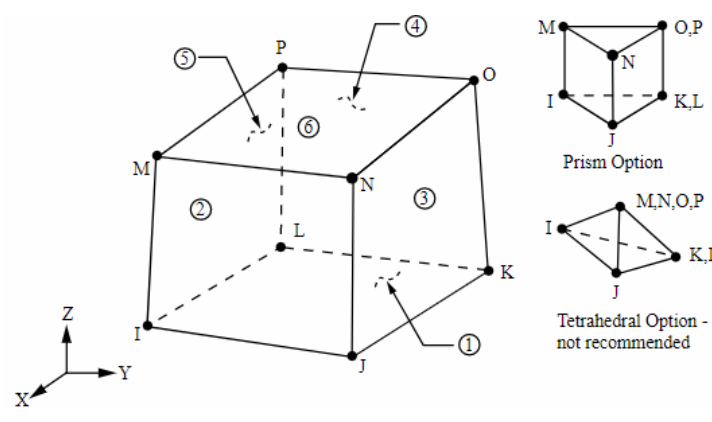

Prism Option

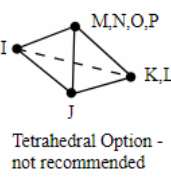

Fonte Ansys (2013a)

Na modelagem da armadura foram empregados os elementos lineares do tipo REINF264, indicados para análises com presença de armadura. A este tipo de elemento pode-se associar parâmetros relativos à plasticidade, fluência, grandes deflexões e grandes deformações. A Figura 6, a seguir, ilustra o elemento REINF264.

Figura 6. Elemento REINF264.
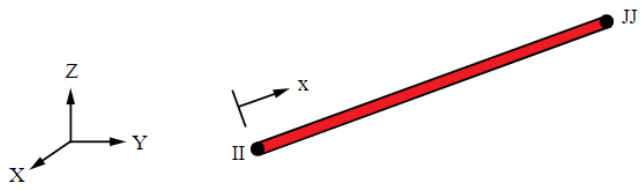

Fonte: Ansys (2013a).

O maciço de solo foi simulado com elementos do tipo SOLID65, elemento padrão adotado do programa para objetos sólidos (ANSYS, 2011). É representado por um prisma de 6 ou 8 nós que apresenta três graus de liberdade em cada nó. A Figura 7, abaixo, apresenta o elemento SOLID65 em detalhes:

Figura 7. Detalhe do elemento SOLID65.

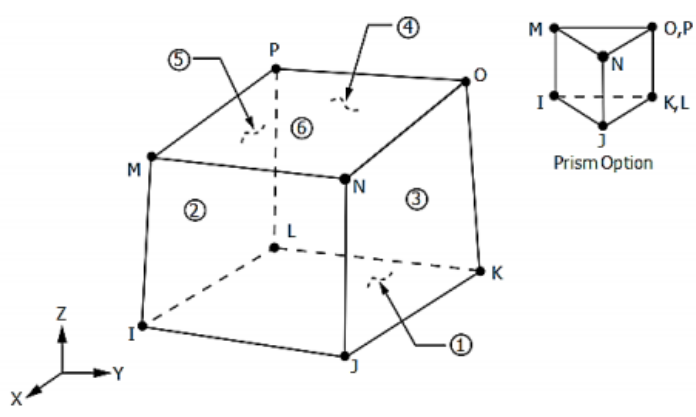

Fonte: Ansys (2011).

\subsection{Carregamentos e combinações}

Foram adotados carregamentos típicos de uma torre eólica metálica com cubo de altura igual a 80,00 m e rotor com diâmetro igual a $86,00 \mathrm{~m}$. Considerando um sistema de eixos cuja origem coincide com o centroide da base do bloco, e o eixo Y representa a direção vertical, as solicitações resultantes transmitidas à fundação são: força horizontal $\mathrm{F}_{\mathrm{xz}}$ (resultante das forças horizontais atuando no plano XZ); momento $\mathrm{M}_{\mathrm{xz}}$ (resultante dos momentos agindo entorno dos eixos $\mathrm{X}$ e $\mathrm{Z}$ ) e força vertical $\mathrm{F}_{\mathrm{y}}$ devido às cargas gravitacionais, como mostra a Figura 8: 
Figura 8. Representação simplificada das cargas transmitidas da torre para o bloco.

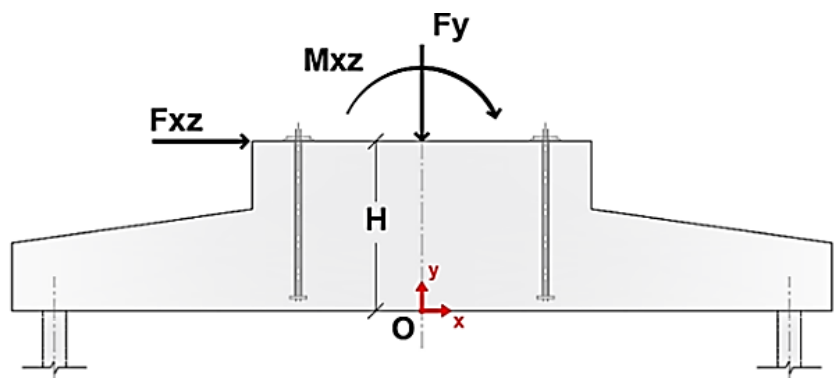

Fonte: Autores (2022).

$\mathrm{Na}$ Tabela 4, apresentam-se os valores característicos adotados para as cargas transmitidas ao bloco, considerando uma situação de produção de energia com vento em velocidade extrema, cujo período de recorrência é 50 anos.

Tabela 4. Cargas transmitidas ao bloco de fundação devido a estrutura do aerogerador.

\begin{tabular}{cc}
\hline Solicitações & Cargas extremas \\
\hline Força Axial $\left[\mathrm{F}_{\mathrm{y}}\right]$ & 2478,00 \\
Momento $-\mathrm{M}_{\mathrm{xz}}[\mathrm{kN} . \mathrm{m}]$ & 45066,00 \\
Força Cortante $\mathrm{F}_{\mathrm{xz}}[\mathrm{kN}]$ & 622,00 \\
\hline
\end{tabular}

Fonte: Araújo (2018)

$\mathrm{O}$ momento aplicado no encontro entre a base da torre e o bloco foi o momento total de tombamento $\left(\mathrm{M}_{\text {total }}\right)$, composto pelo somatório do momento $\mathrm{M}_{\mathrm{xz}}$ com o momento adicional causado pela força cortante $\mathrm{F}_{\mathrm{xz}}$ em relação ao eixo de tombamento da base, como indicado na Equação 2:

$$
M_{\text {total }}=M_{x z}+F_{x z} x H
$$

Dessa forma, o momento total apresentou um valor de $46.932 \mathrm{kNm}$. O efeito translacional devido a força cortante $\left(\mathrm{F}_{\mathrm{xy}}\right)$ foi desconsiderado nas análises, admitindo-se que o empuxo passivo no contato solo/bloco é suficiente para impedir o deslocamento, sendo contabilizado apenas o seu efeito de tombamento na parcela adicionada ao momento.

\section{Dimensionamento}

\subsection{Considerações iniciais}

Segundo Leonhardt e Mönnig (1978), os blocos de coroamento, em geral, têm uma altura definida em função da distância entre as estacas, de modo que se formem bielas de compressão entre a peça que transmite a carga (pilares) e as estacas. Quando isto acontece, os blocos são ditos como rígidos. Como as bielas apresentam um ângulo de inclinação, suas componentes horizontais devem ser absorvidas por tirantes armados com barras ou com cabos de protensão, premissa básica para o dimensionamento das armaduras principais dos blocos.

Para verificar a possibilidade de aplicação da metodologia de bielas e tirantes, realizou-se, em primeiro lugar, a classificação do bloco em estudo de acordo com a ABNT NBR 6118:2014. A norma brasileira apresenta, no seu item 22.6.1, o critério para a classificação de sapatas segundo a sua geometria. O limite estabelecido para a altura das sapatas, também aplicável aos blocos de coroamento, é apresentado na Expressão 3: 


$$
h \geq \frac{\left(a-a_{p}\right)}{3}
$$

Onde:

h - Altura do bloco;

a - Dimensão do bloco em uma determinada direção;

$a_{p}$ - Dimensão do pilar na mesma direção.

Para o bloco em análise, tem-se:

$$
\frac{\left(a-a_{p}\right)}{3}=\frac{(14,5-4,38)}{3}=3,37
$$

Uma vez que a altura h do bloco é igual a 3,0 m, a condição de bloco rígido não é atendida. Alternativamente, se considerado o comprimento diametral entre as estacas $(13,0 \mathrm{~m})$, o diâmetro do pedestal $(6,0 \mathrm{~m})$ como a dimensão do pilar, e a altura do bloco até a região das faces inclinadas (1,80 m), tem-se:

$$
\frac{\left(a-a_{p}\right)}{3}=\frac{(13,0-6,0)}{3}=2,33
$$

Novamente, o critério para classificação como bloco rígido não é atendido. A fundação em estudo, portanto, é classificada como um bloco flexível.

Carvalho e Figueiredo Filho (2013) indicam que em blocos flexíveis formam-se duas ou mais bielas de compressão para conduzir a carga do pilar a cada estaca. Os autores destacam que o dimensionamento de blocos flexíveis não segue a hipótese tradicional de bielas e tirantes, e deve ser realizado com base na Teoria Geral da Flexão para placas e vigas.

\subsection{Primeira concepção: Armadura circular}

Para o caso de fundações circulares de aerogeradores onshore, caracterizadas pela ação de momentos fletores de grande magnitude, faz-se necessário a idealização de um modelo de cálculo próprio para o dimensionamento das armaduras. Puel (2016) propõe a adoção de um modelo simplificado, composto por treliças planas lançadas sobre os eixos das estacas e conectadas entre si, de modo a formar uma estrutura espacial condizente com as características geométricas do bloco.

A Figura 9 apresenta o modelo de treliça idealizado para o bloco em estudo. As diagonais foram lançadas respeitando

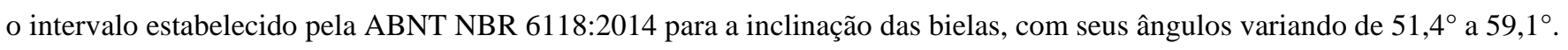

Figura 9. Modelo de treliça idealizado para o bloco.

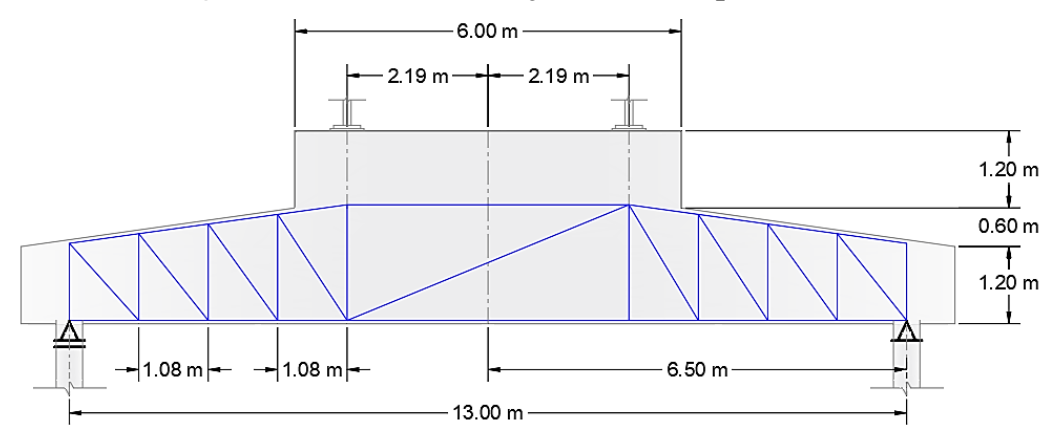

Fonte: Autores (2022). 
O modelo de treliça foi simulado com a utilização do software SAP2000. Às barras, foi associada uma seção genérica e colocadas rótulas em todos os nós, de forma que fossem observados apenas esforços de tração e compressão.

Os carregamentos foram inseridos como cargas concentradas aplicadas nos nós da treliça, na posição correspondente de cada ação. Por se tratar de um modelo destinado ao dimensionamento das armaduras, Puel (2016) recomenda que seja analisado num estado crítico de carregamento, com o emprego de uma combinação em Estado Limite Último (ELU), apresentada na Tabela 5, com os esforços já majorados:

Tabela 5. Carregamentos adicionados ao modelo de barras.

\begin{tabular}{ccccc}
\hline$\gamma \mathbf{f}$ & Peso Próprio [kN] & Faterro $[\mathbf{k N}]$ & Forre $_{\text {tkN] }}$ & M tombamento $[\mathbf{k N}]$ \\
\hline 1,4 & 9556,4 & 2739,8 & 3469,2 & 65704,8 \\
\hline
\end{tabular}

Fonte: Araújo (2018).

Com a treliça mais solicitada como referência, que, neste caso, é a que conecta as estacas E1 e E13, definiu-se seções onde os esforços de tração e compressão foram medidos. Figura 10 apresenta o diagrama de esforços normais na treliça considerada, bem como a indicação das seções de referência.

Figura 10. Diagrama de esforços normais e seções de referência.

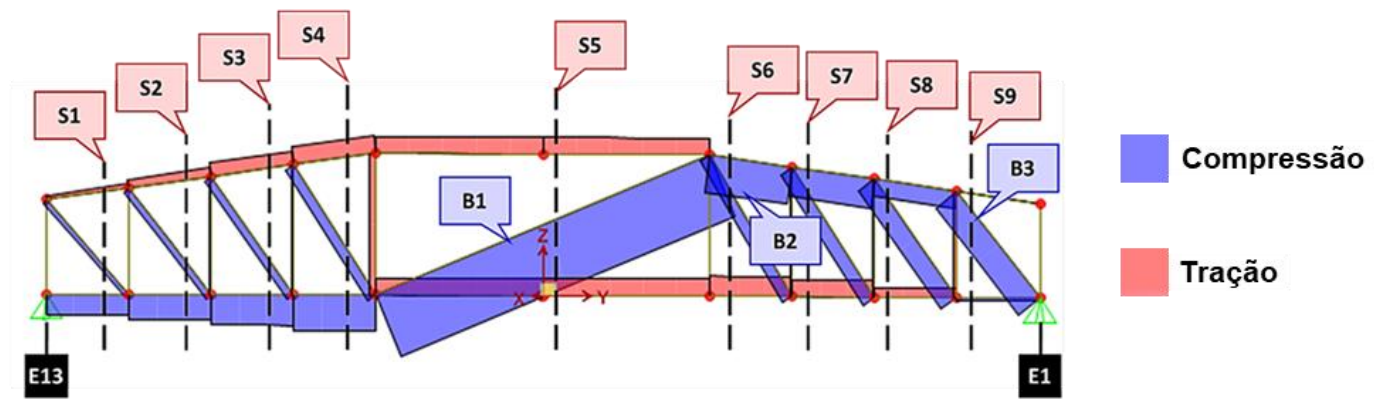

Fonte: Autores (2022).

Os esforços máximos de tração das seções foram registrados na Tabela 6. A partir tirantes, as armaduras radiais do bloco foram calculadas, considerando a tensão de escoamento do aço CA-50.

Tabela 6. Armadura radial inferior.

\begin{tabular}{ccccc}
\hline Seção & $\mathbf{N}[\mathbf{k N}]$ & As,inf. calculada $\left[\mathbf{c m}^{2}\right]$ & As,inf. adotada $\left[\mathbf{c m}^{2}\right]$ & $\mathbf{N}^{\circ}$ e Diâm. das barras p/ setor \\
\hline S5 & 1107,6 & 25,47 & 29,45 & $6 \emptyset 25 \mathrm{~mm}$ \\
S6 & 1292,86 & 29,74 & 29,45 & $6 \varnothing 25 \mathrm{~mm}$ \\
S7 & 1067,71 & 29,74 & 24,54 & $5 \emptyset 25 \mathrm{~mm}$ \\
S8 & 583,86 & 13,43 & 14,73 & $3 \emptyset 25 \mathrm{~mm}$ \\
\hline
\end{tabular}

Fonte: Autores (2022).

De forma análoga, foram calculadas as armaduras circunferenciais da face inferior do bloco, distribuídas nas regiões de influência de cada barra. A Figura 11, a seguir, apresenta o diagrama dos esforços normais e a indicação dos anéis de referência. 
Figura 11. Diagrama de esforços normais nas barras inferiores do modelo de treliça.

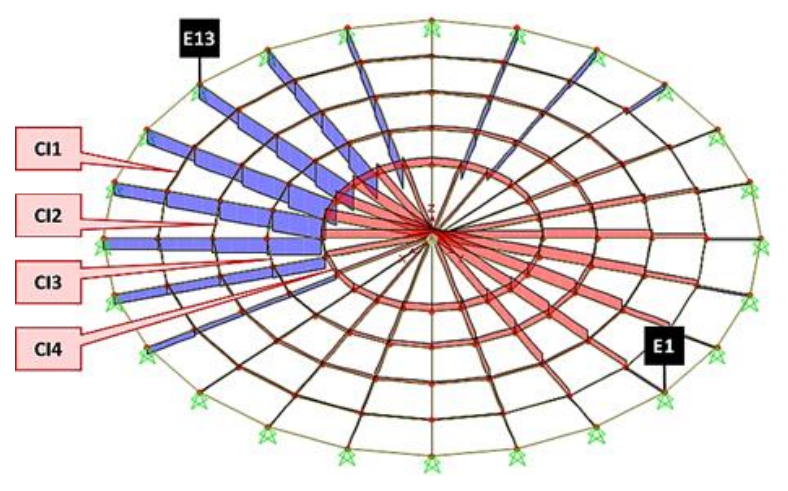

Compressão

Tração

Fonte: Autores (2022).

A Tabela 7 apresenta os esforços máximos em cada anel e as armaduras calculadas:

Tabela 7. Armadura circunferencial inferior.

\begin{tabular}{ccccc}
\hline Seção & $\mathbf{N}[\mathbf{k N}]$ & As,inf. calculada $\left[\mathbf{c m}^{2}\right]$ & As,inf. adotada $\left[\mathbf{c m}^{2}\right]$ & $\mathbf{N}^{\circ}$ e Bitola das barras p/ setor \\
\hline CI1 & 231,96 & 5,34 & 12,57 & $4 \emptyset 20 \mathrm{~mm}$ \\
CI2 & 268,54 & 6,18 & 12,57 & $4 \emptyset 20 \mathrm{~mm}$ \\
CI3 & 653,54 & 15,03 & 15,71 & $5 \emptyset 20 \mathrm{~mm}$ \\
CI4 & 715,45 & 16,46 & 18,85 & $6 \emptyset 20 \mathrm{~mm}$ \\
\hline
\end{tabular}

Fonte: Autores (2022).

\subsection{Segunda concepção: Armadura ortogonal}

Blocos de coroamento podem ser dimensionados com as armaduras principais de flexão dispostas em malhas de duas direções, seja com barras interligando as estacas ou distribuídas por toda a área inferior da fundação. Araújo (2010) indica que para sapatas e blocos flexíveis, pode-se aplicar a teoria geral da flexão, onde as armaduras principais são obtidas através de um dimensionamento à flexão simples. Dadas as dimensões consideráveis da fundação em estudo, a determinação dos esforços para o cálculo das armaduras foi realizada através do chamado Método de Ruptura.

Enquanto em metodologias tradicionais de dimensionamento as armaduras superiores dos blocos de coroamento têm função predominantemente construtiva, sendo muitas vezes calculadas como uma porcentagem da armadura principal de flexão, o Método de Ruptura auxilia na determinação de eventuais momentos negativos, para os quais as armaduras superiores devem ser dimensionadas (Koerich, 2019).

Souza (2004) descreve o Método de Ruptura como uma adaptação da teoria elástica para a determinação dos esforços e armaduras em blocos de fundação, cujo comportamento é admitido como semelhante ao de uma viga e as estacas são representadas por apoios simples.

Para utilização do Método de Ruptura faz-se necessário, numa primeira instância, o conhecimento das reações verticais das estacas. As reações foram calculadas a partir da Equação 4, atribuída à Schiel (1957):

$$
R_{e s t, i}=\frac{F_{y}}{N}+\frac{M_{z} \cdot x_{i}}{\sum x_{i}^{2}}+\frac{M_{x} \cdot z_{i}}{\sum z_{i}^{2}}
$$

Onde:

$\mathrm{R}_{\text {est,i }}$ - Reação vertical na estaca "i” de coordenadas xi e yi;

$\mathrm{F}_{\mathrm{y}}$ - Força vertical resultante (incluindo peso próprio do bloco e o solo de reaterro); 
$\mathrm{n}$ - Número de estacas;

$\mathrm{M}_{\mathrm{x}}$ - Momento em torno do eixo X;

$\mathrm{M}_{\mathrm{z}}-$ Momento em torno do eixo $\mathrm{Z}$.

Todas as ações foram combinadas com seus valores característicos. Como o momento $\mathrm{M}_{\mathrm{xz}}$ é representado por um vetor de seta dupla com a direção do eixo Z, a parcela da Equação 3 que contém o $\mathrm{M}_{\mathrm{x}}$ torna-se nula. Dessa forma, a reação das estacas é calculada levando em consideração apenas a carga vertical e o momento $\mathrm{M}_{\mathrm{z}}$. Os resultados obtidos estão na Tabela 8:

Tabela 8. Reações verticais calculadas nas estacas.

\begin{tabular}{|c|c|c|c|c|c|}
\hline Estaca & $\mathrm{Xi}[\mathrm{m}]$ & $\mathbf{Z i}[\mathrm{m}]$ & N/ne [kN] & $(\mathrm{Mz}, \mathrm{xi}) / \mathbf{\Sigma} \mathbf{x i}^{2}[\mathrm{kN}]$ & $\mathbf{R}_{\text {est }, \mathrm{i}}[\mathrm{kN}]$ \\
\hline E1 & 6,50 & 0,00 & 469,21 & 601,69 & 1070,90 \\
\hline E2 & 6,28 & 1,68 & 469,21 & 581,19 & 1050,40 \\
\hline E3 & 5,63 & 3,25 & 469,21 & 521,08 & 990,29 \\
\hline E4 & 4,60 & 4,60 & 469,21 & 425,46 & 894,67 \\
\hline E5 & 3,25 & 5,63 & 469,21 & 300,85 & 770,05 \\
\hline E6 & 1,68 & 6,28 & 469,21 & 155,73 & 624,94 \\
\hline E7 & 0,00 & 6,50 & 469,21 & 0,00 & 469,21 \\
\hline E8 & $-1,68$ & 6,28 & 469,21 & $-155,73$ & 313,48 \\
\hline E9 & $-3,25$ & 5,63 & 469,21 & $-300,85$ & 168,36 \\
\hline E10 & $-4,60$ & 4,60 & 469,21 & $-425,46$ & 43,75 \\
\hline E11 & $-5,63$ & 3,25 & 469,21 & $-521,08$ & $-51,87$ \\
\hline E12 & $-6,28$ & 1,68 & 469,21 & $-581,19$ & $-111,98$ \\
\hline E13 & $-6,50$ & 0,00 & 469,21 & $-601,69$ & $-132,48$ \\
\hline
\end{tabular}

Fonte: Autores (2022).

A Figura 12 apresenta os diagramas de força cortante e momento fletor determinados nas duas direções: 
Figura 12. Diagramas de força cortante e momento fletor.

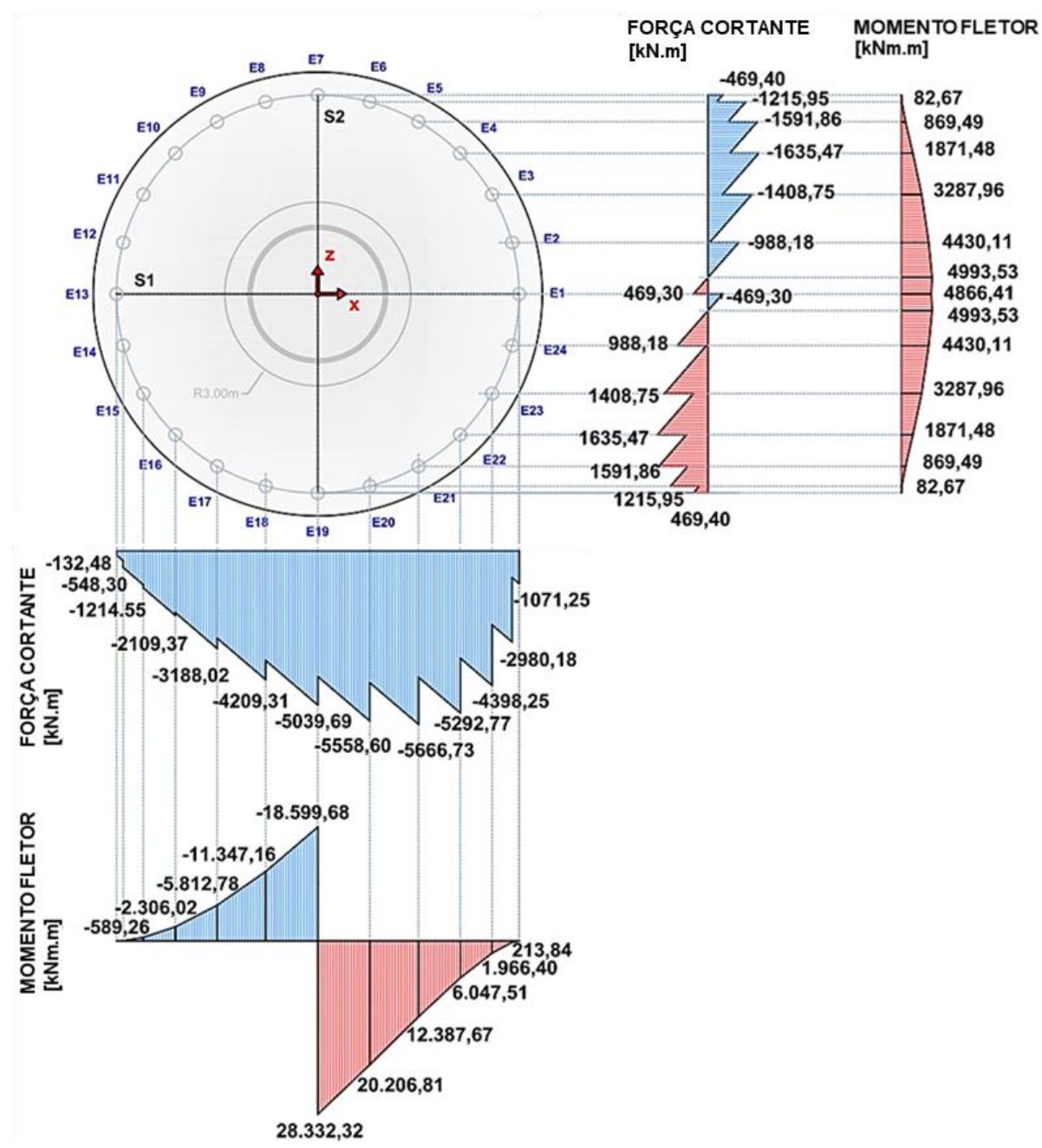

Fonte: Autores (2022).

Para o dimensionamento das armaduras, foi considerada uma faixa unitária do bloco, representada por uma viga cuja seção possui altura de 3,0 m e largura de 1,0 m. Devido a possibilidade da mudança de direção do vento, as armaduras paralelas ao eixo $\mathrm{X}$ foram replicadas no eixo $\mathrm{Z}$, de modo a formar uma malha ortogonal homogênea. A Tabela 9 apresenta o resultado do dimensionamento das armaduras realizado com base no plano de referência $\mathrm{S} 1$.

Tabela 9. Armaduras longitudinais calculadas pelo Método de Ruptura.

\begin{tabular}{ccccc}
\hline $\mathbf{M}_{\mathbf{d}}[\mathbf{k N m}]$ & $\mathbf{A}_{\text {s,inf. Calculada }\left[\mathbf{c m}^{2}\right]}$ & $\mathbf{A}_{\text {s,inf. Adotada }\left[\mathbf{c m}^{2}\right]}$ & $\mathbf{N}^{\circ}$ e Diâm. das barras p/ setor & Espaçamento [cm] \\
\hline $28.332,32$ & 364,13 & 387,79 & $75 \emptyset 25 \mathrm{~mm}$ & 18,0 \\
\hline
\end{tabular}

Fonte: Autores (2022).

\subsection{Resumo}

A Tabela 10 apresenta um resumo das armaduras calculadas nas duas concepções consideradas: 
Tabela 10. Resumo das armaduras.

\begin{tabular}{cccccc}
\hline Armadura Circular & Comprimento [m] & Peso [kg] & Armadura Ortogonal & Comprimento [m] & Peso [kg] \\
\hline Radial & 690,82 & 2763,30 & X Inferior & 950,36 & 3801,42 \\
Circunferencial & 707,22 & 1768,06 & Z Inferior & 950,36 & 3801,42 \\
\hline Total & 1398,04 & 4531,36 & Total & 1900,72 & 7602,84 \\
\hline
\end{tabular}

Fonte: Autores (2022).

As armaduras principais de flexão adicionadas aos modelos são mostradas na Figura 13:

Figura 13. Armaduras dos modelos: (a) Malha Circular. (b) Malha ortogonal.

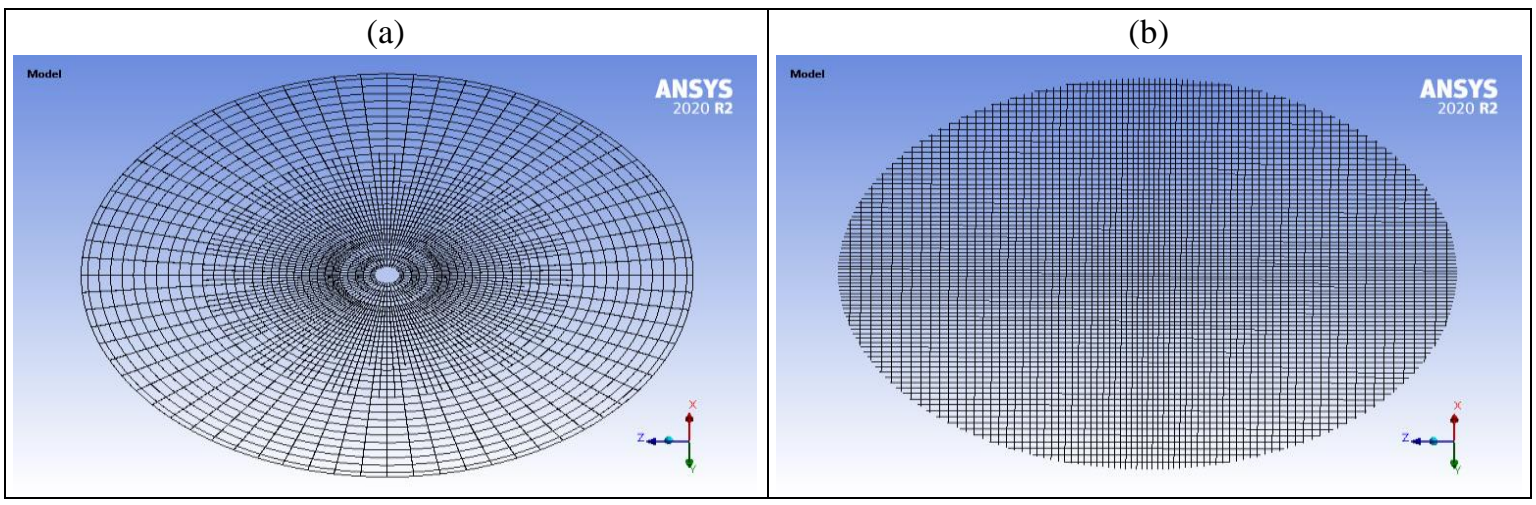

Fonte: Fonte: Autores (2022).

\section{Resultados e Discussão}

\subsection{Considerações iniciais}

A numeração das estacas foi atribuída de maneira que a E1 sempre fosse a estaca comprimida com maior reação vertical e a direção dos eixos X e Z, que definem o plano da face inferior do bloco, fosse definida com base na posição da E1, conforme indicado na Figura 14. Foram determinadas as reações verticais nas estacas, em diferentes tipos de solo, os deslocamentos verticais dos blocos e das estacas mais solicitadas, as regiões de fissuração do concreto e as tensões nas armaduras.

Figura 14. Sistema de eixos e numeração das estacas.

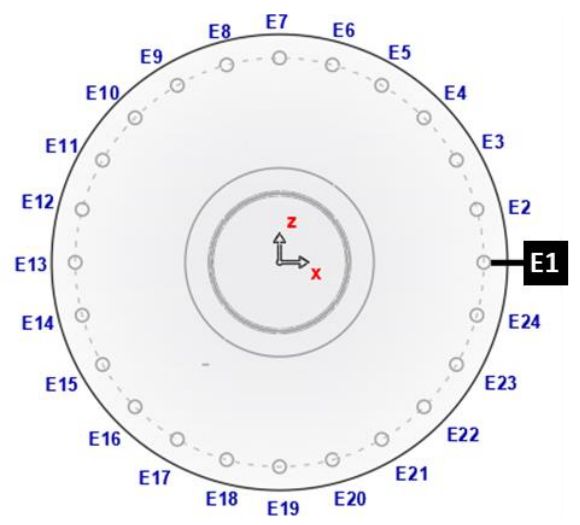

Fonte: Autores (2022).

Buscou-se, quando possível, comparar os resultados das análises com aqueles obtidos por Araújo (2018), uma vez que as fundações analisadas possuem a mesma geometria e carregamentos. O comportamento estrutural dos blocos foi, também, comparado com o previsto pelos modelos de cálculo apresentados nos itens 3.2 e 3.3 . 


\subsection{Reações verticais das estacas}

As reações verticais na base das estacas, para os diferentes modelos, são apresentadas na Tabela 11. Os resultados obtidos para os modelos simulados com armaduras circulares (AC) e ortogonais (AO) foram comparados com aqueles obtidos por Araújo (2018), que modelou blocos sem a presença de armadura. Foram inseridas, na coluna "ANALÍTICO", as reações determinadas a partir de Equação 4. Dada a simetria, a Tabela 11 apresenta as reações computadas até a $13^{\mathrm{a}}$ estaca.

Tabela 11. Reações verticais das estacas nos diferentes modelos.

\begin{tabular}{|c|c|c|c|c|c|c|c|c|c|c|c|c|}
\hline \multirow[b]{2}{*}{ Est. } & \multirow[b]{2}{*}{$\begin{array}{l}\text { Analít. } \\
{[\mathrm{kN}]}\end{array}$} & \multicolumn{2}{|c|}{ SEM SOLO } & \multicolumn{3}{|c|}{ SOLO S1 } & \multicolumn{3}{|c|}{ SOLO S2 } & \multicolumn{3}{|c|}{ SOLO S3 } \\
\hline & & $\begin{array}{c}\text { S0_AC } \\
{[\mathrm{kN}]}\end{array}$ & $\begin{array}{c}\text { S0_AO } \\
{[\mathrm{kN}]}\end{array}$ & $\begin{array}{c}\text { S1 } \\
\text { ARAÚJO } \\
(\mathbf{2 0 1 8}) \\
{[\mathbf{k N}]}\end{array}$ & $\begin{array}{c}\text { S1_AC } \\
{[\mathrm{kN}]}\end{array}$ & $\begin{array}{c}\text { S1_AO } \\
{[\mathrm{kN}]}\end{array}$ & $\begin{array}{c}\text { S2 } \\
\text { ARAÚJO } \\
(2018) \\
{[\mathrm{kN}]}\end{array}$ & $\begin{array}{c}\text { S2_AC } \\
{[\mathrm{kN}]}\end{array}$ & $\begin{array}{c}\text { S2_AO } \\
{[\mathrm{kN}]}\end{array}$ & $\begin{array}{c}\text { S3 } \\
\text { ARAÚJO } \\
(\mathbf{2 0 1 8}) \\
{[\mathbf{k N}]}\end{array}$ & $\begin{array}{r}\text { S3_AC } \\
{[\mathrm{kN}]}\end{array}$ & $\begin{array}{r}\text { S3_AO } \\
{[\mathrm{kN}]}\end{array}$ \\
\hline E1 & 1070,90 & 1061,36 & 1062,08 & 1014,4 & 249,21 & 207,62 & 956,74 & 131,30 & 108,47 & 830,68 & 77,09 & 63,13 \\
\hline E2 & 1050,40 & 1041,01 & 1041,77 & 995,04 & 242,83 & 194,21 & 936,95 & 126,95 & 96,20 & 814,98 & 74,19 & 54,17 \\
\hline E3 & 990,29 & 981,22 & 982,13 & 938,41 & 232,57 & 177,70 & 882,75 & 123,87 & 86,96 & 768,85 & 73,26 & 48,55 \\
\hline E4 & 894,67 & 887,85 & 885,96 & 848,28 & 209,14 & 172,96 & 797,63 & 111,38 & 91,36 & 695,33 & 66,02 & 53,59 \\
\hline E5 & 770,05 & 764,93 & 762,64 & 730,66 & 180,76 & 146,40 & 687,04 & 97,386 & 76,15 & 599,11 & 58,17 & 43,69 \\
\hline E6 & 624,94 & 621,13 & 618,95 & 593,45 & 144,62 & 116,50 & 558,12 & 77,17 & 59,21 & 486,32 & 45,18 & 32,44 \\
\hline E7 & 469,21 & 465,53 & 464,98 & 445,81 & 119,88 & 98,83 & 419,12 & 68,66 & 55,07 & 363,97 & 42,16 & 32,37 \\
\hline E8 & 313,48 & 308,91 & 309,38 & 297,60 & 78,21 & 71,45 & 278,93 & 43,01 & 40,72 & 239,55 & 24,12 & 23,97 \\
\hline E9 & 168,36 & 162,39 & 163,26 & 158,83 & 47,63 & 40,66 & 146,68 & 27,12 & 22,50 & 120,98 & 15,57 & 12,36 \\
\hline E10 & 43,75 & 36,36 & 36,64 & 39,15 & 15,64 & 13,84 & 31,63 & 9,04 & 7,85 & 17,02 & 4,88 & 4,16 \\
\hline E11 & $-51,87$ & $-60,11$ & $-60,76$ & $-52,96$ & $-9,17$ & $-7,36$ & $-57,81$ & $-4,63$ & $-3,51$ & $-64,01$ & $-2,95$ & $-2,14$ \\
\hline E12 & $-111,98$ & $-120,69$ & $-121,92$ & $-110,98$ & $-24,29$ & $-20,46$ & $-113,06$ & $-12,73$ & $-10,39$ & $-115,46$ & $-7,35$ & $-5,77$ \\
\hline E13 & $-132,48$ & $-141,28$ & $-142,79$ & $-130,78$ & $-30,36$ & $-24,26$ & $-131,94$ & $-16,82$ & $-12,03$ & $-133,1$ & $-10,29$ & $-6,38$ \\
\hline
\end{tabular}

Fonte: Autores (2022).

Nota-se que, de modo geral, as reações nos modelos simulados com solo apresentaram maior uniformidade, com os valores de pico reduzidos a um patamar comum nas estacas comprimidas e tracionadas. As máximas reações verticais das estacas comprimidas, dos modelos AC, apresentaram uma diminuição de 76,52\%, 87,63\% e 92,74\%, nos solos S1, S2 e S3, respectivamente, em relação ao modelo simulado sem solo, S0_AC. Já nos modelos AO, as divergências com o modelo S0_AO, para os solos S1, S2 e S3, foram de 80,45\%, 89,79\% e 94,05\%, respectivamente.

Tal fenômeno foi atribuído à consideração do recalque das estacas, por meio da introdução de apoios elásticos nas suas bases, associado à aderência com o maciço, visto que nos modelos simulados sem solo, com estacas apresentando apoios fixos nas pontas, a distribuição das reações apresentou grande similaridade ao modelo analítico. As maiores divergências observadas entre as reações dos modelos S0_AC e S0_AO, com os valores determinados através da Expressão 4.2, foram de 16,9\% e 17,13\%, respectivamente.

Os dados da Tabela 11 foram representados graficamente na Figura 15: 
Figura 15. Reações verticais das estacas nos diferentes modelos.

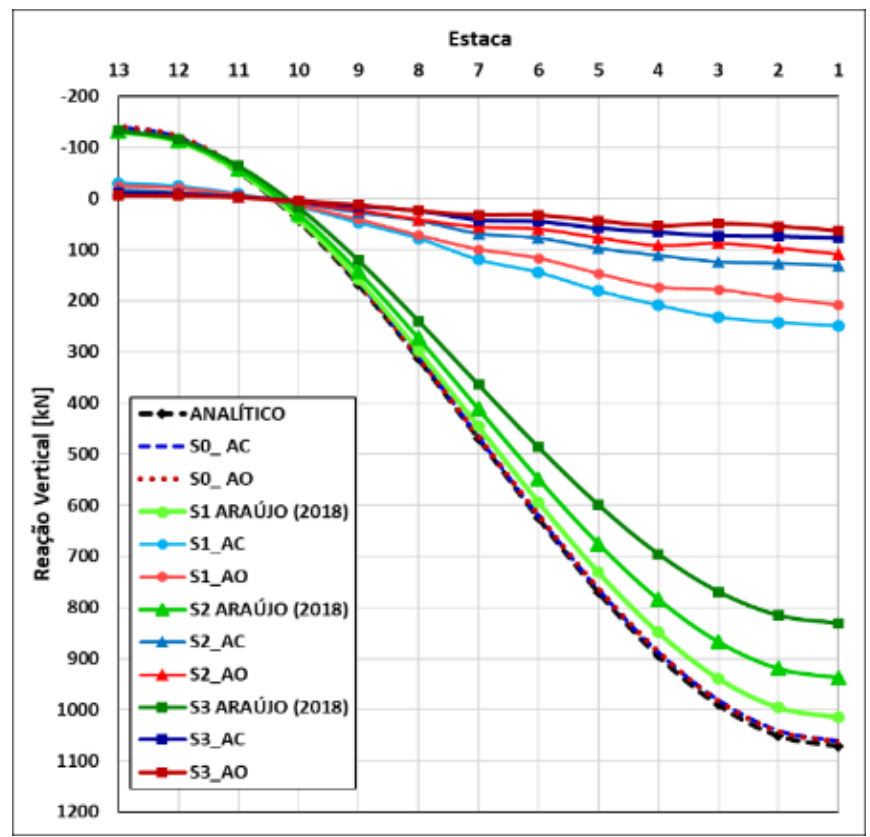

Fonte: Autores (2022).

Observar-se que o aumento da rigidez do solo acentuou a uniformização das reações verticais nas estacas comprimidas, diminuindo valores de pico, ao passo que foi mantido o aumento na reação das estacas tracionadas, conforme o solo tornou-se mais rígido. Sob esta óptica, pode-se dizer que o maciço de solo atuou como uma camada de regularização, fato que pode ser observado também nos resultados obtidos por Araújo (2018). Nos modelos com armadura circular, as maiores divergências entre as reações máximas das estacas tracionadas, em relação ao modelo sem solo, foram de 78,51\%, 88,10\% e 92,72\%, nos solos $\mathrm{S} 1$, S2 e S3, respectivamente, e de $83,01 \%, 91,56 \%$ e $95,53 \%$, para os modelos simulados com armadura disposta em malha ortogonal.

\subsection{Deslocamentos verticais do bloco}

Os deslocamentos verticais dos modelos apresentaram o padrão mostrado na Figura 16, onde os valores mínimos e máximos assinalados delimitam o comprimento diametral que interliga as estacas E1 e E13, respectivamente.

Figura 16. Representação dos deslocamentos verticais por faixas de isovalores.

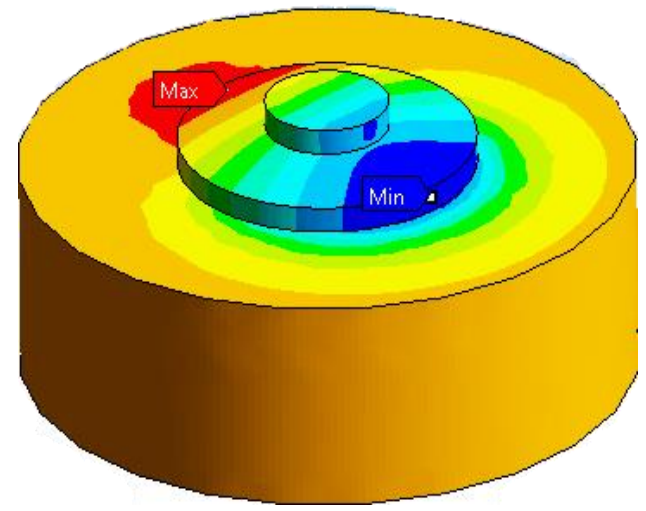

Fonte: Autores (2022). 
Em razão da consideração do atrito entre as fundações e o solo ter sido atribuída apenas às faces laterais das estacas, pôde-se observar, nas simulações, regiões de descolamento dos blocos em relação ao maciço (deslocamentos positivos) e regiões de afundamento (deslocamentos negativos). O deslocamento vertical da face inferior do bloco, para os diferentes modelos, é apresentado, graficamente, na Figura 17. A faixa considerada corresponde ao comprimento diametral entre as estacas E1 e E13.

Figura 17. Deslocamento vertical da base do bloco nos diferentes modelos.

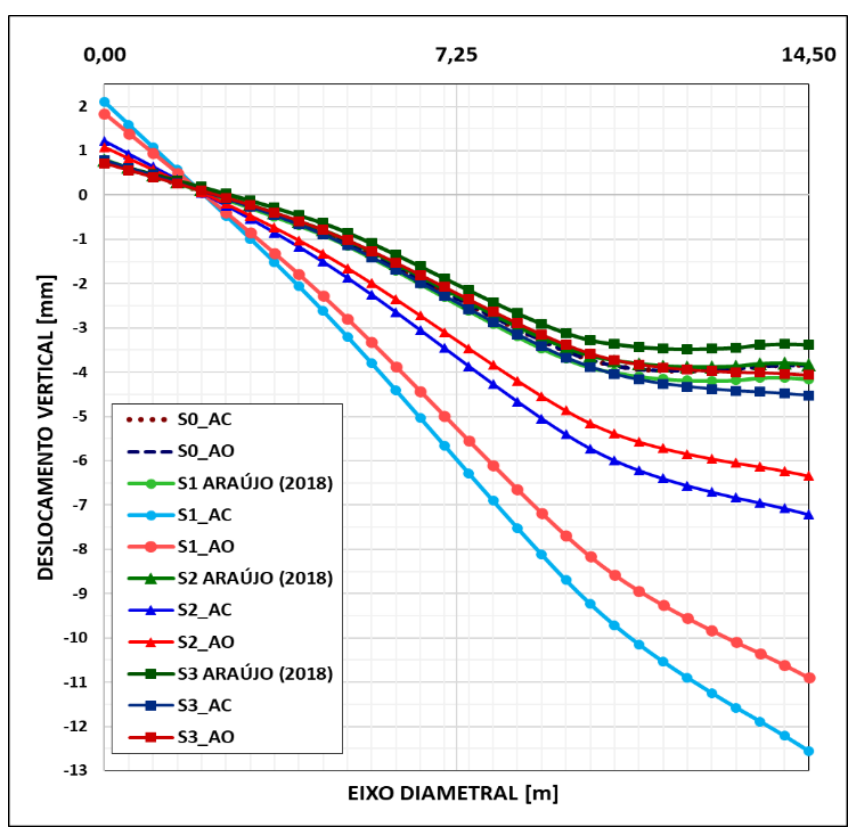

Fonte: Autores (2022).

A partir da Figura 17, pode-se distinguir três trechos lineares nas curvas que descrevem os deslocamentos verticais ao longo do diâmetro do bloco: o primeiro na região tracionada, com deslocamentos verticais positivos, o segundo numa região intermediária comprimida e o terceiro na região mais extrema comprimida, ambos com deslocamentos verticais negativos.

Na região tracionada, nota-se que as retas apresentam inclinações cada vez menores à medida que o solo é enrijecido. Nas zonas comprimidas, para uma mesma curva, a diferença entre as inclinações dos dois trechos lineares também aumenta com a acréscimo da rigidez do solo. Dessa forma, o trecho linear na região mais extrema comprimida torna-se quase horizontal, no solo S3, com bastante proximidade dos resultados de Araújo (2018).

De modo geral, a região comprimida intermediária apresenta maior rigidez por representar o trecho da base sob o pedestal, por isso ocorrem maiores acréscimos na deformação. Igualmente, a região comprimida extrema menor rigidez por se situar fora da projeção do pedestal, ocorrendo menores acréscimos de deformação.

Como as variações das deformações são quase que lineares, fica caracterizado o comportamento de elemento rígido, mesmo o bloco sendo classificado como flexível segundo o critério estabelecido pela ABNT NBR 6118:2014. Além disso, ficam caracterizados também dois trechos no interior do bloco com distintas rigidezes: um na região da projeção do pedestal; e outro na região fora dessa projeção; sendo esse aspecto intensificado com o acréscimo de rigidez do solo. O padrão assumido pelas curvas dos modelos $\mathrm{AC}$ e $\mathrm{AO}$ apresenta, novamente, um indício de que a distribuição $\mathrm{AO}$ forneceu ao bloco maior rigidez à flexão.

Na Tabela 12 foram registrados os valores máximos e mínimos dos deslocamentos verticais observados ao longo do diâmetro do bloco, e foram calculadas as deformações acumuladas totais, pela da diferença entre eles. 
Tabela 12. Deslocamentos verticais dos blocos entre as estacas E1 e E13.

\begin{tabular}{cccc}
\hline \multirow{2}{*}{ Modelo } & & Deslocamento vertical [mm] & Diferença \\
\cline { 2 - 4 } S0_AC & Mínimo & Máximo & 4,75 \\
S0_AO & $-3,98$ & 0,77 & 4,76 \\
S1_ARAÚJO (2018) & $-3,98$ & 0,78 & 5,00 \\
S1_AC & $-4,19$ & 0,81 & 14,66 \\
S1_AO & $-12,56$ & 2,10 & 12,73 \\
S2_ARAÚJO (2018) & $-10,90$ & 1,84 & 4,68 \\
S2_AC & $-3,89$ & 0,79 & 8,43 \\
S2_AO & $-7,21$ & 1,22 & 7,42 \\
S3_ARAÚJO (2018) & $-6,34$ & 1,08 & 4,25 \\
S3_AC & $-3,48$ & 0,77 & 5,31 \\
S3_AO & $-4,53$ & 0,79 & 4,78 \\
\hline
\end{tabular}

Fonte: Autores (2022).

Semelhante ao que foi observado na Figura 15, os modelos AO apresentaram maior uniformidade dos deslocamentos verticais, com menor amplitude entre valores máximos e mínimos. Os modelos AC tiveram uma amplitude dos deslocamentos verticais superior aos modelos AO em $15,16 \%$, no solo S1, 16,61\% no S2 e 11,09\% no S3.

É possível verificar, também, que, à medida que o solo se tornou mais rígido, a introdução das armaduras teve menor influência nos deslocamentos verticais dos blocos. No solo S1, as maiores divergências entre os deslocamentos verticais negativos dos modelos AC e AO, em relação ao modelo S1 de Araújo (2018), que simulou um bloco sem armaduras, foram de, respectivamente, $202,17 \%$ e $162,08 \%$. No S2, a diferença foi de $85,35 \%$ e 62,98\%, e, no S3, de 30,17 e 16,95\%. Tal fenômeno é decorrente da atuação do maciço como uma camada de regularização, que é acentuada conforme aumentada sua rigidez.

\subsection{Fissuração do concreto}

Na Figura 18, a seguir, podem ser visualizadas as regiões onde se deram as deformações plásticas do concreto tracionado (Equivalent Plastic Strain) no modelo S1_AC, que, pela nomenclatura adotada pelo programa, são associadas à fissuração. A distribuição das fissuras foi confrontada com a Figura 10, que apresenta o diagrama de esforços normais do modelo de treliça considerado no dimensionamento.

Figura 18. Regiões de fissuração do concreto comparadas com o modelo de treliça.

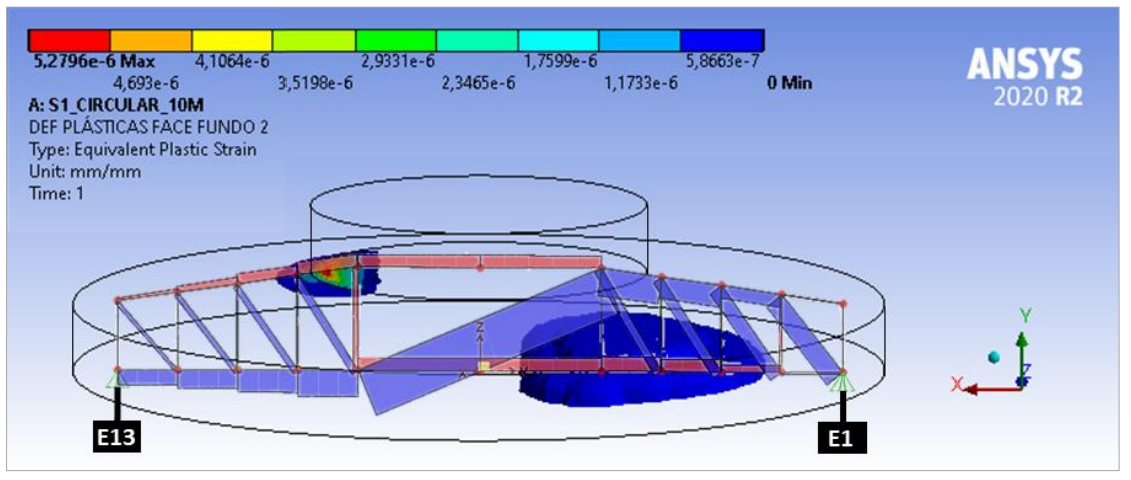

Fonte: Autores (2022). 
A Figura 18 mostra a compatibilidade entre o modelo de barras e o modelo de elementos finitos tridimensionais, em relação à distribuição das tensões na fundação. Nota-se que a fissuração na porção superior do bloco, entre a saia e o pedestal, ocorreu numa região muito restrita e que as fissuras não se propagaram em direção ao centro do bloco. Tal comportamento é explicado pelo fato de haver um maior volume de concreto nessa região, suficiente para resistir aos esforços de tração.

Os gráficos da Figura 19 apresentam a evolução das deformações plásticas do concreto tracionado (Equivalent Plastic Strain), em mm/mm, ao longo da aplicação da carga. O eixo vertical (Normalized) faz referência às frações do carregamento aplicado (substeps) e cada ponto dos gráficos representa uma iteração realizada pelo programa, onde o modelo convergiu.

Figura 19. (a) Fissuração na face inferior do bloco, ao longo da aplicação da carga (b) Tensões nas armaduras inferiores.

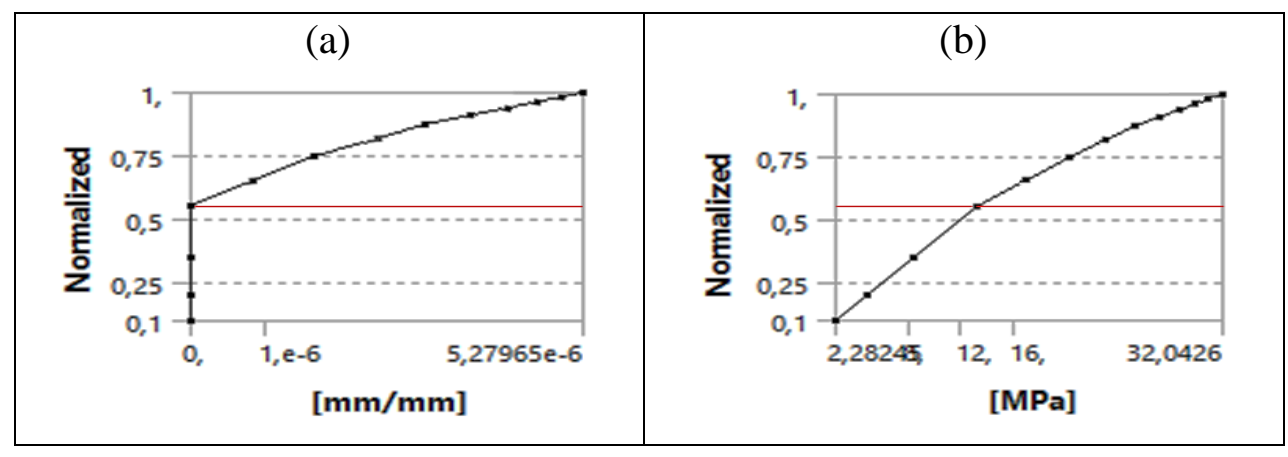

Fonte: Autores (2022).

A partir da Figura 19(a), é possível constatar que a fissuração do concreto se iniciou, na face inferior do bloco, com cerca de 55\% do carregamento aplicado, na quarta iteração realizada pelo programa. Neste mesmo estágio do carregamento notase, pela Figura 19(b), que as armaduras inferiores passaram a ser mais solicitadas, o que resultou numa mudança de inclinação das retas que descrevem as máximas tensões de tração ao longo do carregamento.

É importante destacar que os incrementos de carga desiguais se devem ao fato de ter-se promovido uma análise do tipo step by step, onde cada iteração é realizada numa situação de equilíbrio. Devido a isso, o número de iterações aumentou consideravelmente após o início da fissuração, em razão da redistribuição de esforços.

\subsection{Tensões nas armaduras}

O padrão da distribuição das tensões nas armaduras inferiores é apresentado na Figura 20. Nela, vê-se que, conforme esperado, as maiores tensões de tração se deram nas zonas de fissuração do concreto, indicadas na Figura 18.

Figura 20. Distribuição das tensões nas armaduras inferiores: (a) Malha circular. (b) Malha ortogonal.

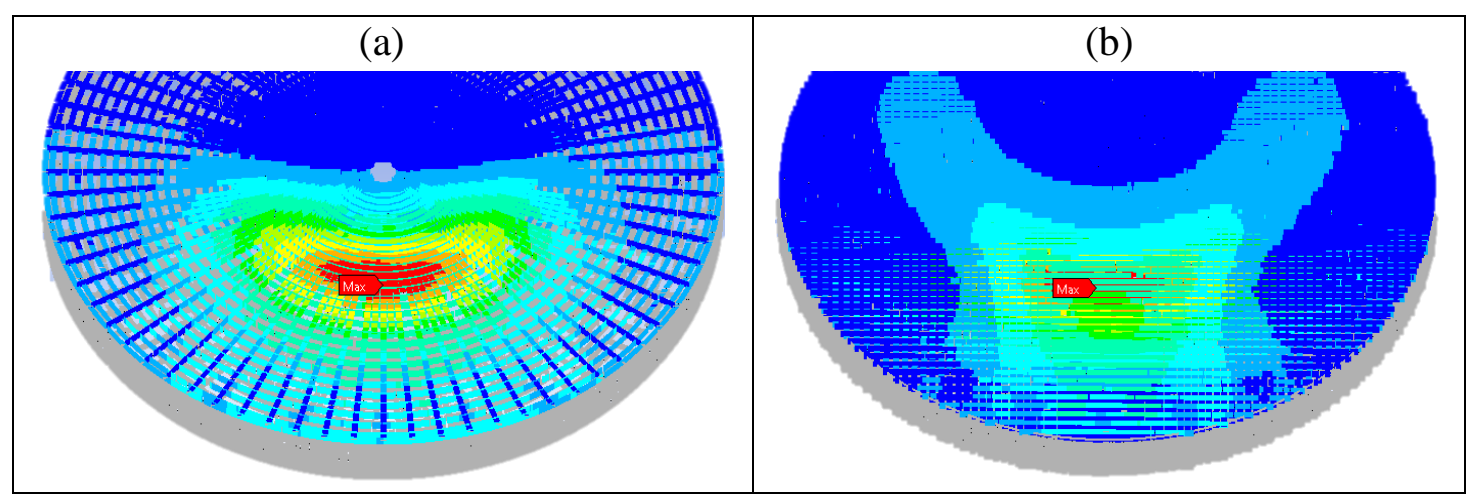

Fonte: Autores (2022). 
A Figura 21 expressa, graficamente, a relação entre as máximas tensões de tração nas armaduras e a resistência do solo:

Figura 21. Tensões máximas nas armaduras inferiores em diferentes tipos de solo.

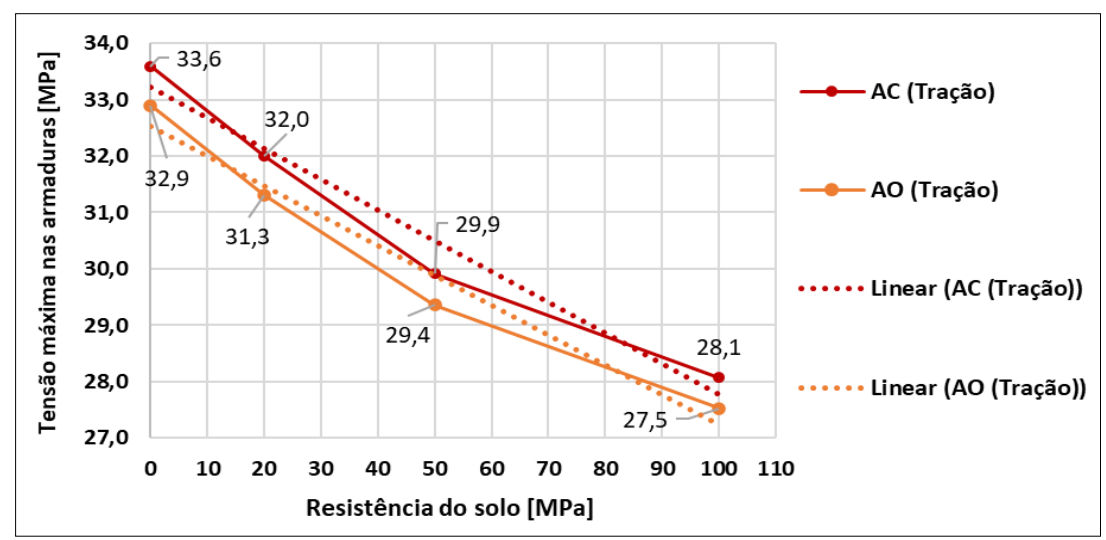

Fonte: Autores (2022).

Pode-se constatar, pela Figura 21, que as maiores tensões se deram nos modelos com armadura circular, superiores, em média 2,06\% aos modelos com armadura ortogonal. Tal tendência remete ao fato dos modelos AO terem se mostrado mais rígidos que os modelos $\mathrm{AC}$ que, sendo mais deformáveis, impõem às armaduras maiores esforços quando fletidos pelo momento de grande magnitude que atua na fundação.

A diminuição das tensões nas armaduras, à medida que o solo é enrijecido, está relacionada ao fato de o maciço atuar como uma camada de regularização. Uma vez que a armadura inferior combate, sobretudo, a flexão da face inferior do bloco, a diminuição dos deslocamentos verticais promovida pelo solo, alivia as tensões nessas armaduras.

\section{Conclusão}

O presente estudo teve como objetivo principal a análise do comportamento estrutural de fundações de aerogeradores onshore, representas por blocos circulares de concreto armado apoiados estacas, com a utilização de simulações numéricas baseadas no Método dos Elementos Finitos, que consideraram a não linearidade física dos materiais e o atrito com o solo.

Em princípio, foi avaliada a influência da rigidez do solo na distribuição das reações nas bases das estacas. Os resultados mostraram que, de modo geral, houve uma diminuição da carga conduzida às estacas e, consequentemente, um aumento da participação do bloco na dispersão de cargas diretamente ao solo, à medida que o maciço se tornou mais rígido.

Ainda que o bloco analisado tenha sido classificado como flexível, segundo critérios da ABNT NBR 6118:2014, o padrão de distribuição linear observado para os deslocamentos verticais foi compatível com o comportamento de blocos rígidos, fato que foi associado à atuação do maciço de solo como uma camada de regularização, além da rigidez fornecida pelas armaduras introduzidas aos modelos. As divergências entre os deslocamentos verticais dos modelos armados indicaram que a distribuição das armaduras em malha ortogonal tornou o bloco mais rígido, o que já era esperado em razão da maior quantidade de aço.

A consideração da não linearidade física dos materiais do bloco permitiu mapear as zonas de fissuração do concreto, que foram consistentes com as regiões onde se observou as máximas tensões de tração nas armaduras. A formação e propagação das fissuras, ao longo da aplicação do carregamento, também esteve diretamente relacionada com o nível de solicitação imposto às armaduras que, embora não tenham atingido o escoamento, passaram a ser mais tensionadas à medida que o concreto fissurou.

Para continuidade do estudo desenvolvido, sugere-se avaliar a influência dos parafusos protendidos, que fazem a ancoragem da torre, no comportamento estrutural da fundação, além da natureza dinâmica dos carregamentos. 
Research, Society and Development, v. 11, n. 2, e0711223146, 2022

(CC BY 4.0) | ISSN 2525-3409 | DOI: http://dx.doi.org/10.33448/rsd-v11i2.23146

\section{Agradecimentos}

O presente trabalho foi realizado com apoio da Coordenação de Aperfeiçoamento de Pessoal de Nível Superior - Brasil (CAPES) - Código de Financiamento 001.

\section{Referências}

ABNT - Associação Brasileira De Normas Técnicas. ABNT NBR 6118: Projeto de estruturas de concreto - procedimento, Rio de Janeiro, 2014.

Agra Neto, J., Queiroz, F. C. B. P., Queiroz J. V., Lima; N. C., \& Silva, C. L. (2020). Evolução e perspectivas do setor eólico no Brasil: análise dos principais estados produtores. Revista em Agronegócio e Meio Ambiente, 13 (4), 1409-1432.

Ansys (2011). ANSYS Mechanical APDL Element Reference. Canonsburg: ANSYS Inc.

Ansys (2013a). ANSYS Mechanical APDL Advanced Analysis Guide. Canonsburg: ANSYS Inc.

Ansys (2013b). ANSYS Mechanical APDL Structural Analysis Guide. Canonsburg: ANSYS Inc.

Ansys (2013c). ANSYS Mechanical APDL Theory Reference. Canonsburg: ANSYS Inc.

Araújo, J. M. (2010). Curso de Concreto Armado (2a ed.). Dunas.

Araújo, K. Y. M. (2018). Análise do comportamento estrutural de blocos de concreto armado sobre estacas como fundação para aerogerador onshore. (Dissertação de Mestrado). Universidade Federal do Rio Grande do Norte, Natal, 2018.

Carvalho, R. C., \& Figueiredo Filho, J. R. (2013). Cálculo e detalhamento de estruturas usuais de concreto armado (2a ed.). Pini.

Chastre, C., \& Lúcio, V. (2014). Evolução histórica, desenvolvimento atual e potencial futuro das torres de concreto pré-moldado para suporte de aerogeradores. Concreto \& Construções, XLII (75), 24-34.

Décourt, L. (1996). Análise e projeto de fundações profundas. In: Hachich, A. et al. (Eds.). Fundação: teoria e prática. Pini.

International Energy Agency. (2021). Global Energy Review 2021. https://www.iea.org/reports/global-energy-review-2021.

Koerich, M. M. (2019). Novo critério para o dimensionamento de blocos de fundação com pilares associados. https://next.altoqi.com.br/destaque/novocriterio-para-o-dimensionamento-de-blocos-de-fundacao-com-pilares-associados/.

Leonhardt, F., \& Mönnig, E. (1978). Construções de Concreto: Princípios básicos de estruturas de concreto armado. Interciência.

Mendizabal, R. L. (2014). Realizações do concreto no setor eólico. Revista Concreto \& Construções, XLII (75), 42-48.

Milititsky, J. (2014). Desafios na solução de fundações de aerogeradores. Revista Concreto \& Construções, XLII (75), 49-61.

Nakamura, J. (2020). Resistência e durabilidade pautam a construção de torres eólicas. https://www.aecweb.com.br/revista/materias/resistencia-edurabilidade-pautam-a-construcao-de-torres-eolicas/20458.

Puel, A. (2016). Base de aerogeradores: Comparativo de dimensionamento modelo mef e modelo biela/tirante. Anais do IX Congresso Brasileiro de Pontes e Estruturas, Rio de Janeiro.

Schiel, F. (1957). Estática das construções. Escola de Engenharia de São Carlos.

Souza, R. A. (2004). Concreto estrutural: análise e dimensionamento de elementos com descontinuidades. (Tese de Doutorado). Universidade de São Paulo, São Paulo. 